This article reports a study of aggregate unit salary levels, within a major research university. We analyze these salary levels, as they are influenced by unit sex composition, and modified by unit attainment levels - where unit refers to the departments, colleges and schools, and other academic divisions of the university. We investigate three central issues of sex and salary, previously overlooked in salary studies of academic employees: Do high proportions of women depress men's unit salary levels ("competition" hypothesis)? Are women's salary levels higher in male-dominated, and lower in female-dominated, units ("concentration" hypothesis)? Are men salary-compensated for ("compensation" hypothesis)? The findings support none of these hypotheses. Rather. the relationship between unit sex composition and salary rests upon the connection between units' composition and attainment levels.

\title{
Sex Segregation and Salary Structure in Academia
}

\author{
MARY FRANK FOX \\ University of Michigan
}

n America, as in other societies, work and economy are sex segregated (Friedl, 1975; Rosaldo, 1974; Tavris and Offir, 1977). While the female component of the American labor force has greatly expanded, the sex composition of the labor force has not, correspondingly, desegregated. Occupations were as segregated in 1970 as they were in 1900; at both times, the majority of American working women have been employed at jobs in which at least $70 \%$ of their fellow workers are female (Blau, 1978).

Like other work, in most places, work in academia is also sex segregated. Academic women are not only concentrated in the

Author's Note: This article is a revised version of a paper presented at the annual meeting of the American Sociological Association, Boston, Massachusetts, August 1979. For her reading and helpful comments on an earlier version of this article, I am grateful to Mary E. Corcoran. 
lower-ranking positions, but also within a limited number of places-largely, within the arts, humanities, and language departments, and the professional schools, aligned with education, public health, and welfare areas (Astin and Bayer, 1973; Fox, 1978; Murlock, 1973; Patterson, 1973).

This article addresses not simply the existence, or documentation, of academic sex segregation, but rather its major concomitant: salary levels. We report a study of aggregate, university unit ${ }^{1}$ salary levels as they are influenced by unit sex composition, and modified by unit achievement, or attainment, levels. We regard these unit sectors as occupational subclassifications and locations for academic employees.

The achievement standard and performance norm prevail throughout American society (Williams, 1960; Parsons and White, 1961; Lipset, 1963; Rytina et al., 1970). But, in academia, these values predominate (Merton, 1949; Caplow and McGee, 1958; Barber, 1952; Cole and Cole, 1973). Academia is America's home of the "scientific ethos," which, in turn, expresses the culture's achievement ideology in its purest form (Barber, 1952; Cole and Cole, 1973). Consequently, in academia, if anywhere, we expect to find a close approximation of the universalistic ideal; a disinterest in distinctions not founded in ability and achievement; and a commitment to performance, as a standard of evaluation and reward.

Thus, in this income study, we regard attainment levels as "legitimate" determinants of academic reward; and sex composition as an ascriptive, and hence "illegitimate," reward determinant.

We then aim to determine whether a salary advantage or disadvantage of unit sex composition (an ascriptive characteristic of the group doing the work) may be attributed to higher or lower unit achievement (i.e., nonascriptive attainment) characteristics. In other words, we determine not only whether a sex composition and salary relationship exists, but also whether this effect is exonerated by a "legitimate" rationale.

Other microeconomic (single-institution) studies of academics have documented salary variation by sex (Ferber and Loeb, 1971; Reagan and Maynard, 1974; Ferber et al., 1978), but none of these studies is aggregate, either in data unit or issue. Our study, 
on the other hand, represents an analysis, micro in its organizational and occupational context, and aggregate in its data unit and sex-salary focus. This combination of features permits us to pose and investigate certain sex-salary issues, previously overlooked for academic employees.

The single-institution feature limits generalizability of findings to smaller, more minor institutions. However, in another way, the restriction is advantageous. The single-institution data, by definition, holds constant institutional affiliation, which is a major factor differentiating the research productivity levels of academics generally (Long, 1978), and male and female academics, more particularly (Bernard, 1964; Astin, 1969; Tsuchigane and Dodge, 1974). Hence, the data allow us to hold constant, at some threshold, unit levels of male and female productivity.

The aggregate data feature, on the other hand, allows us to study academic income at an important salary-determining level-the university unit location. This, in turn, permits us to focus upon certain structural aspects of sex, salary, and segregation, as they operate in the academic reward system.

\section{SEX COMPOSITION AND UNIT SALARY: THE HYPOTHESES}

More specifically, the study focuses upon three issues:

(1) Do high proportions of women depress men's unit salary levels?

(2) Are women's salary levels higher in male-dominated, and lower in female-dominated, units?

(3) Are men compensated by salary for working with women?

We address and discuss these issues by testing three, nonmutually exclusive, hypotheses, referred to as (1) "competition"; (2) "concentration"; and (3) "compensation."

\section{COMPETITION: SEX COMPOSITION AND MALE SALARY}

Investigations of the salary concomitants of occupational sex composition have focused upon the salary consequences for 
men-the group presumably at risk. Correspondingly, we have hypothesized an inverse relationship between the proportion of women in the academic unit and the unit's male salary level.

The salary effect of minority group (black and female) employees is said to be a "competitive process," insofar as a minority competes with the majority group for jobs and is willing to accept wages below those demanded by white males (Hodge and Hodge, 1965). There is some argument about whether the process is best called "competitive," since "segregation" may restrict minority group admission into high-paying professions, and thus force their entry into already lower-paying occupations. Hence, "segregation," rather than "competition," may be the causal process accounting for the observed relationship between (higher) minority group composition, and (lower) majority group income (Snyder and Hudis, 1976; Taeuber et al., 1966; Weiskoff, 1972; Zellner, 1972).

We are more interested, however, in the relationship between minority group composition and male salary than in causal attribution of the relationship to "competition" or "segregation." Still, the attribution is consequential, insofar as competition offers economic rationale, rather than arbitrary prejudice, as an explanation for the discrimination of a minority by the male majority group.

If female composition of a profession or employment unit has injurious effects upon the salaries if men, discrimination behavior may represent more than "normative preference" for males; it may be an economic response and defense. Then the ostensible welcome of males to the ranks of librarians and social workers, and the blocked access of women to traditional professions of medicine and law, might be regarded as a attempt to maintain or advance the economic status of a profession.

\section{CONCENTRATION: SEX COMPOSITION AND FEMALE SALARY}

Feminine sex-typed occupations, by definition, have higher proportions of women. They also have lower occupational 
prestige and income levels (Coser and Rohoff, 1971; Collins, 1971; Weiskoff, 1972). Accordingly, we have hypothesized that the average unit salary of academic women (as well as men) will be lower in units with higher proportions female.

Reflecting their general oversight of women in stratification (Acker, 1973), sociologists have directed much less attention to the association between female (as opposed to male) salary and sex segregation. Yet the economic literature does indicate an inverse relationship between female occupational composition and salary level (Fuchs, 1971; Kohen and Roderick, 1972; Stevenson, 1975).

The relationship between female salary and segregation has been attributed to a "crowding" process, first suggested by early twentieth-century British economists (Fawcett, 1918; Edgeworth, 1922), and recently revived and expanded by Bergmann and other American economists (Stevenson, 1975). The crowding theory argues that women's low wages result from restricted access to most occupations, and hence overcrowding of a few remaining jobs. This oversupply of women for these limited opportunities then artificially reduces wages in these females sectors (Stevenson, 1975, 1978).

This economic argument overlaps and extends the issue of the concentration of women in low-paying places. Our hypothesis, however, refers to the relationship between female unit salary and female composition, which does not, in itself, imply concentration as discussed by the economists; women may have lower salaries in employment units with high female proportions, but if those are relatively small units, they may not contain a majority of the employed women.

\section{COMPENSATION: SEX COMPOSITION AND THE RATIO OF FEMALE TO MALE SALARY}

Economic literature suggests a market and employment preference for males and a distaste for females (Becker, 1971; Kohen et al., 1975; Madden, 1973). We might then reason that men who do work with women will be compensated with salaries higher 
than those of the women in their employment unit. Accordingly, we hypothesize a lower ratio of female to male salary in academic units with higher concentrations of women.

"Compensation" might then be regarded as a kind of hardship pay given to men employed in units with an undesirable working condition. The payment can make evident the superordinate status of men, and hence retain these "preferred" (male) employees in units with "undesirable" (female) composition.

This does not suggest that men in feminine sectors are rewarded at a higher rate than men in masculine sectors; the competition hypothesis proposes otherwise. But this compensation hypothesis does suggest that men employed in feminine sectors have higher salaries relative to the women in their units than do men in masculine sectors.

\section{METHOD}

\section{DATA}

The data source for these analyses is the academic personnel tape for a major midwestern university at one point in time, June 1971. More recent multivariate data are unavailable for study comparison or replication. However, the limited gross data available suggest remarkable stability, rather than change, in the pattern of sex disparity in salary between 1971 and $1978 .{ }^{2}$

The data constitute a group of 30 units, which include the departmental subdivisions of the literary college; the other 17 colleges and schools; and the 7 remaining university, but noncollege, units with academic employees. ${ }^{3}$

While the unit data include both college (or teaching) and noncollege units, data are constituted only by "academic appointments." These appointments refer to all faculty, but to only those particular researchers and administrators, who, while not teaching academicians, have a higher rank on a nonfaculty, but career, ladder. Auxiliary analyses failed to reveal significant salary determination differences between the college versus noncollege 
unit types, hence assuring that our findings are unconfounded by this aspect of the data organization.

To test such salary determination differences, we analyzed an additional salary model, which included a dummy variable for college/noncollege location (along with the other variables discussed subsequently, as "salary model 3"). These auxiliary analyses showed that college variable to be an insignificant determinant of male, female, and female : male unit salary levels. And while the college variable changes the coefficients of the independent income determinants by varying amounts, it does not produce any large, systematic changes in these coefficient levels.

Our organization and aggregation of units represents a functional classification: different institutional task, functions, and roles within the university. For example among noncollege units, the organized research unit engages in scientific inquiry, while the state and public relations unit operates in areas such as university press, publishing, and communication.

Similarly, the classification of college (teaching) units represents various functional, instructional areas, such as the schools of law, business administration, and medicine. Due to its size and internal differentiation, the literary college is further subclassified by department. These departments are aggregated according to functional academic, but also market and economic, communalities. For example: Because of its functional, as well as market, relationship with the humanities, history is coded in this, rather than in the social science, area.

The dependent variables are the average male salary, average female salary, and the ratio of female to male salary within units. These salary measures are monthly rates, referring to the average unit salary levels for full-time employment.

The independent variables are the unit ascriptive (sex) composition, and the unit achievement, or attainment, levels. The ascriptive composition is the proportion unit female. The unit attainments are education and experience (seniority): the proportion of the unit employees with doctorate, medical, or law degrees, and the proportion with six or more years' university service. 
Six or more years is the chosen seniority level, because this is the conventional threshold year for tenure decisions. ${ }^{4}$ This variable, then, enables us to take into partial account the unit salary effect of both the proportion employees tenured, and the proportion above the assistant professor rank. The unit proportion with six or more years of service is, of course, a clearer measure of aggregate seniority than of tenure and rank; new faculty enter the university at higher ranks, and seniority does not invariably indicate rank. Nonetheless, the data do show a positive rank-seniority relationship, with $78 \%$ of the professors, $44 \%$ of the associate professors, $16 \%$ of the assistant professors, and $15 \%$ of the instructors and lecturers having been at the university at least six years.

More importantly, in this study, the seniority variable has the advantage of being applicable across all the university units, teaching and nonteaching, while tenure and professorial rank are characteristics of only the teaching academics.

Having controlled for the (experience and educational) attainment levels, we may then regard intrauniversity units as being higher to lower attaining places. This would be similar to regarding locations within, say, the national forest service or public health corps as having higher to lower rank (i.e., seniority or experience) and educational levels.

\section{ANALYSIS TECHNIQUE}

The unit salary relationships are expressed in multistage regression models. 5 These multistage expressions allow us to compare baseline (coefficient value) relationships between unit proportion female and aggregate unit salary, with the values of subsequent equations which include unit achievement levels. ${ }^{6}$ In this manner, we may explicate and decompose the academic reward structure.

Hence, we first assess the association between aggregate salary level and unit proportion female (model 1). We then determine what happens to the contextual, sex-composition effect: net of aggregate achievements (model 2), and net of sex-related ag- 
gregate achievements (model 3 ). The analyses are directed by the theoretical framework that attainments are the "legitimate" determinants of academic income.

If the effect of proportion unit female (a variable reflecting minority group concentration) is taken up by the effects of achievement, we may conclude that the association between salary and proportion unit female is partly due to unit attainments, and that income may be accounted for, in part, by legitimate determinants. However, if proportion female is a significant determinant of income after we control for unit attainments, there is evidence of illegitimate income determination.

\section{SEX COMPOSTION AND UNIT SALARY: THE FINDINGS}

\section{SEX COMPOSITION AND MALE SALARY}

The sex composition of the unit is, by itself, a significant determinant of male salary: Units with higher proportions of women have significantly lower male salaries (Table 1). This gross sex-salary relationship is then in accord with the competition hypothesis.

However, when we control for the units' educational and seniority profiles (Table 2 ), the negative return on proportion female is reduced by $50 \%(-704.29$ to -343.36$)$. This reduction suggests that half the negative association between proportion female and male salary is due to the lower attainment profiles of units with higher concentrations of women. Proportion female continues to be negatively associated with male salary, but the variable is a less significant income predictor than either the seniority or the educational profile of the unit.

The role of achievements in the determination of male salary really unfolds in the model that separates the unit attainments by sex (Table 3). 
TABLE 1

Regressions of Unit Male and Unit Female Income per Month on Proportion Unit Female

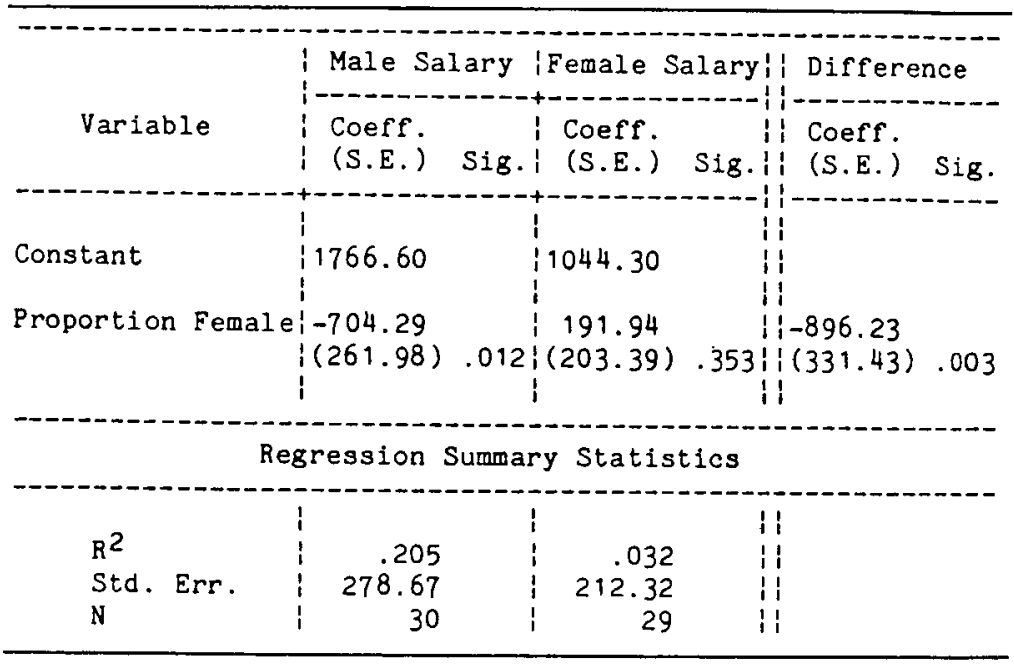

First, this final income model is much stronger than the two preceding. The gross model, with sex composition alone, explained one-fifth of the variation in aggregate male salary; the addition of unit attainments raises the explained variation to onethird; the sex-separation of those attainments, moreover, raises the explained variation to nearly one-half.

Second, in this last model, the negative return on proportion unit female decreases by $74 \%(-343.36$ to -90.47$)$. Consequently, with attainments in the more discrete, sex-separated form, sex composition becomes decidedly insignificant in the determination of male salary.

Third, the statistical relations of this last model show that the unit attainment levels of men, but not of women, are the critical determinants of male salary. For male attainments, the t-statistics (not shown in tables) are higher than the statistics for female attainments, and much higher than the t-statistic for unit proportion female (Table 3 ).

The final model suggests that male achievements upgrade male unit salaries, but that female accomplishments do not. This sex 
TABLE 2

Regressions of Unit Male and Unit Female Income per Month on Proportion Unit Female and Unit Achievements

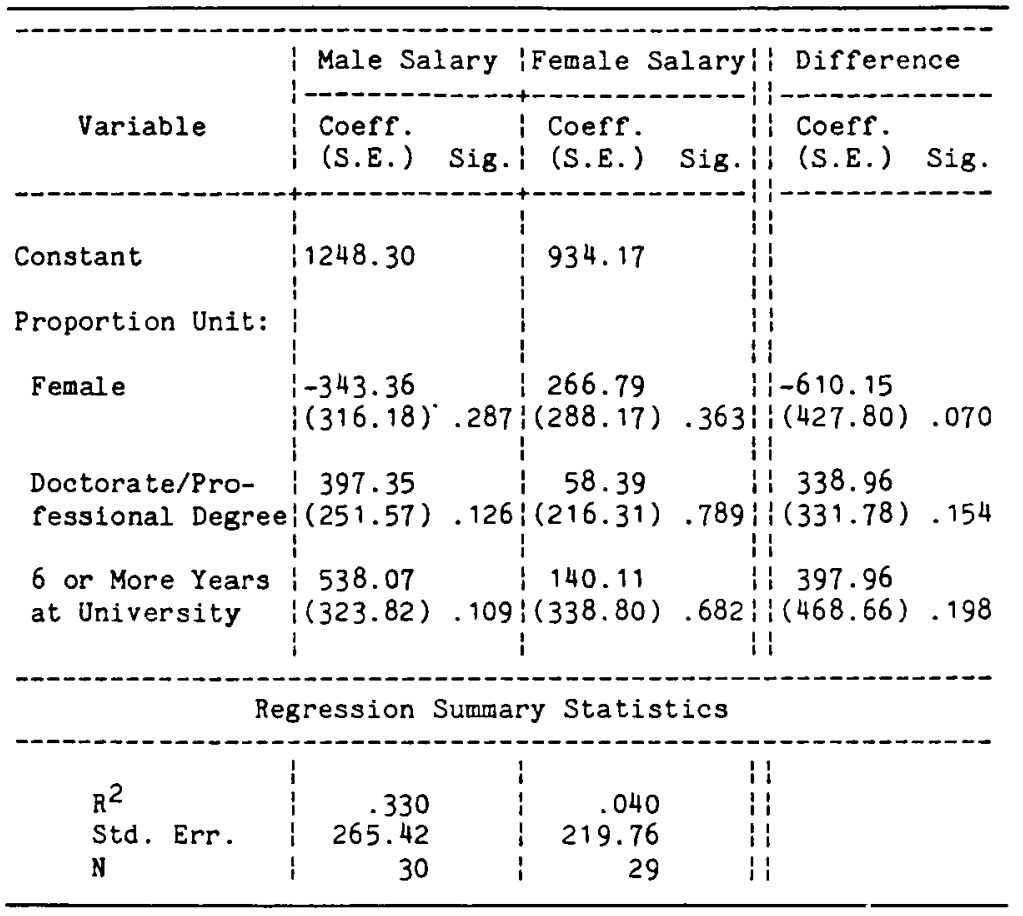

discrepancy is most apparent in the effects of educational attainments. Men's educational attainment is the most important determinant of male unit salary; higher educational levels predict higher salary levels. The higher educational levels of female unit colleagues do not, on the other hand, predict higher male salary levels. Female attainments are actually negatively associated with male salary; the standard error of this education effect is so large, however, that confidence in the particular direction of the effect is not high.

Hence, unit sex composition is important in determining male unit salary, insofar as unit composition is associated with male achievements, especially education: Units with higher proportions of women have relatively low male achievement levels. The 


\section{TABLE 3}

Regressions of Unit Male and Unit Female Income per Month on Proportion Unit Female and Sex-Related Unit Achievements

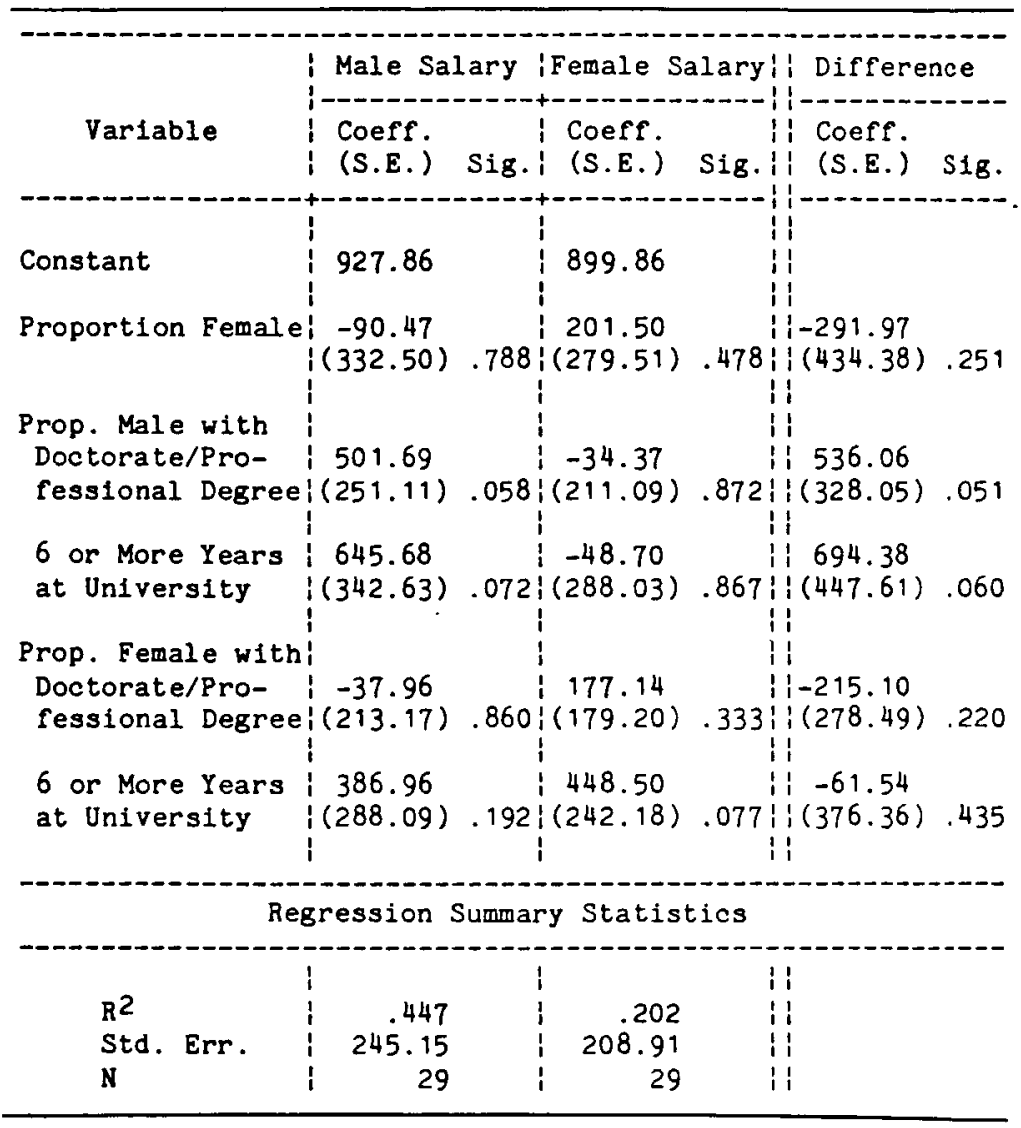

lower male attainments, rather than either the presence or the achievement performance or women, accounts for lower male unit salaries.

\section{SEX COMPOSITION AND FEMALE SALARY}

Units with higher proportions of women have higher female unit salary levels. The direction of this relationship contradicts that of the concentration hypothesis. However, the observed sex- 
salary relationship is not nearly so strong for female as it is for male salary level. Proportion unit female explains only $3 \%$ of the variation in female salary; this variable explains seven times more, $20 \%$, of the variation in male salary (Table 1 ).

The addition of unit achievements, at the second-stage model, increases the $\left(R^{2}\right)$ strength of the female salary model by a mere $.7 \%$, compared to the $12.5 \%$ in the male model. Achievements do increase the sex composition coefficient in the female salary model, but the significance of the effect remains low (Table 2).

The coefficient for proportion female, before and after addition of achievements, is 191.94 and 266.79. While the coefficient increases, the significance level does not; this reflects an increase in the standard error of the variable. Nonetheless, it is the stability in the sex composition effect in the female salary models, compared to change in the male models, that is noteworthy.

Comparison of these second-stage models for women versus men not only indicates that unit sex composition is a less important determinant for women, but that unit attainment levles are also relatively unimportant for women. This is evidenced in comparison of the relative stability of the $R^{2}$ and the sex composition coefficients in the first-and second-stage models for female salary, compared to changes in both measures for male salary.

At this second stage. the unit achievement effects reflect the attainments of all unit employees. Academic employees are predominantly males, and hence average unit achievements are likely to be a measure of male attainment levels. If the attainments of the same sex are the more critical income determinants for female salary level, as they are for male salary, the achievement effect may be masked by the dominance of the opposite sex in these second-stage measures. The third-stage model, with sexseparated attainments removes any masking effect, and elucidates the income-determining process.

First, the income-determining strength of this final female model is much stronger than that of the preceding. While the first and the second models explain only $3 \%$ and $4 \%$ of the female salary variation, the proportion increases to $20 \%$ in the last 
model. This indicates the importance of same-sex attainments in determining female, as well as male, salary.

Of these achievements, seniority emerges as most important for women: Units with high female seniority have higher female salary levels. Education is the next most important incomedetermining variable. Yet in contrast to the decidedly important and significant effect of same-sex education in the male model, the variable is only comparatively important for women; important, that is, in comparison with other income-determining variables.

Furthermore, the same-sex achievements have considerably lower income value for women. The male payments for same-sex educational (501.69) and seniority (645.68) attainments are, respectively, two-thirds and one-third higher than the payments (177.14 and 448.50) for women.

Finally, in this model, we find that attainments of the opposite sex do not determine female salary levels. Male attainments are actualiy negatively associated with female salary. But the statistical significance of the effects is low, leading us to conclude that neither high nor low male achievements predict higher female salary levels.

Hence, the association between proportion unit female and unit female salary is positive, rather than the hypothesized negative. But sex composition is not the significant determinant of the female salary levels between academic units.

Achievements are the more important determinants. Academic units with higher proportions of female employees with doctorates, and with six or more years' seniority, have higher female salary levels. The attainments of male employees, on the other hand, do not affect female aggregate salary. The same-sex attainments are the more important determinants of female, as they are of male, salary; but the income-determining significance and income value returns are not nearly so strong for women as they are for men.

\section{SEX COMPOSITION AND THE RATIO OF UNIT FEMALE: MALE SALARY}

The gross relationship between female unit sex composition and the ratio of unit female : male salary is positive and highly 


\section{TABLE 4}

Regression of Unit Salary-Ratio (Female:Male) on

Proportion Unit Female

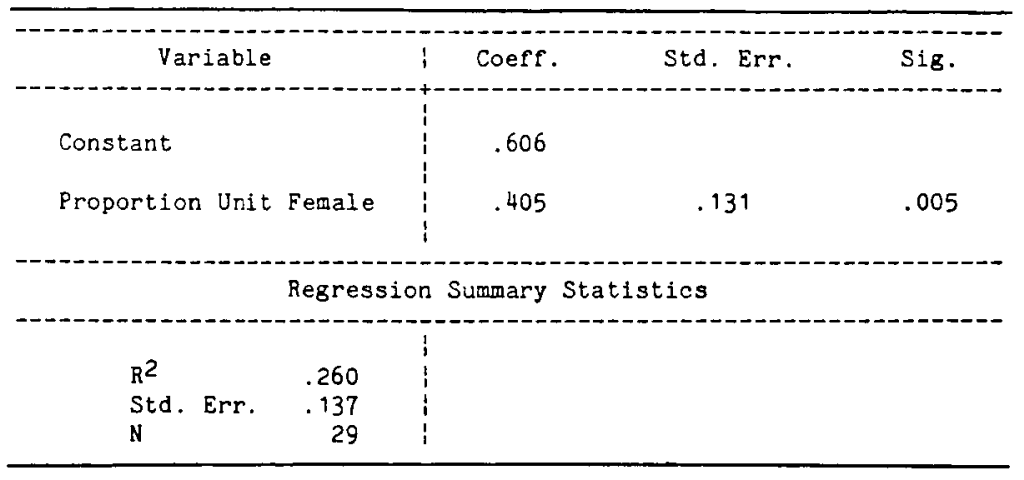

significant (Table 4). Units with higher proportions of women have more equivalent male and female salaries. This first-level finding contradicts the compensation hypothesis.

The addition of unit attainments, at the second-stage model, suggests that these variables are the more important determinants of female : male salary (Table 5).

First, unit attainments greatly strengthen the income model, increasing the explained income variation from $26 \%$ to $40 \%$.

Second, the attainment characteristics are the dominant income determinants. They reduce the strong baseline relationship between proportion unit female and female : male salary to an insignificant level.

Third, the statistical relations for these characteristics indicate confidence in their income-determining effects. The t-statistic levels for both educational and seniority attainments (-1.402; -2.221 ) are higher than the level for proportion female (1.039).

Attainment levels, in this second-stage model, are negatively related to female : male salary. Hence, units with high education and seniority profiles have less equivalent female and male salaries. These unit attainments are not sex-separated. The thirdstage model, however, uncovers the sex-related effect of achievements.

The notable feature of this third model is the opposite way in which male and female achievement levels are related to female : male salary. Male attainments are negatively associated with 
TABLE 5

Regression of Unit Salary-Ratio (Female:Male) on Proportion Unit Female and Unit Achievements

\begin{tabular}{|c|c|c|c|}
\hline Variable & Coeff. & Std. Err. & Sig. \\
\hline Constant & .948 & & \\
\hline Proportion Unit: & 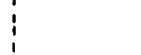 & & \\
\hline Female & .174 & .168 & .308 \\
\hline Doctorate/Professional Degree & -.177 & .126 & .173 \\
\hline 6 or More Years at University & -.439 & 197 & .036 \\
\hline
\end{tabular}

Regression Summary Statistics

$\begin{array}{lrr}\mathrm{R}^{2} & & .400 \\ \text { Std. } & \text { Err. } & .128 \\ \mathrm{~N} & & 29\end{array}$

female-male salary, but female seniority and education are both positively associated with female : male salary (Table 6). These data suggest that units with more equivalent female and male salary levels are locations with higher female, and lower male, achievement profiles.

In summary, the gross (first-stage) relationship between proportion unit female and the female : male salary ratio is strongly positive, and thus in the direction opposite to that predicted by the compensation hypothesis. But, with the addition of unit attainments, the sex composition effect is rendered insignificant, and achievements emerge as the important determinants of female : male salary: Units with higher attainment profiles have less equivalent female and male salary levels.

The achievement reward structure is further revealed when education and seniority profiles are sex-separated in the thirdstage model: Units with more equivalent female and male salaries have lower male attainments, but the female attainments in these salary equivalent units tend to be high. Thus, units with more equivalent female and male salaries tend to be locations with relatively low-attaining men and high-attaining women. 
TABLE 6

Regression of Unit Salary-Ratio (Female:Male) on Proportion Unit Female and Sex-Related Unit Achievements

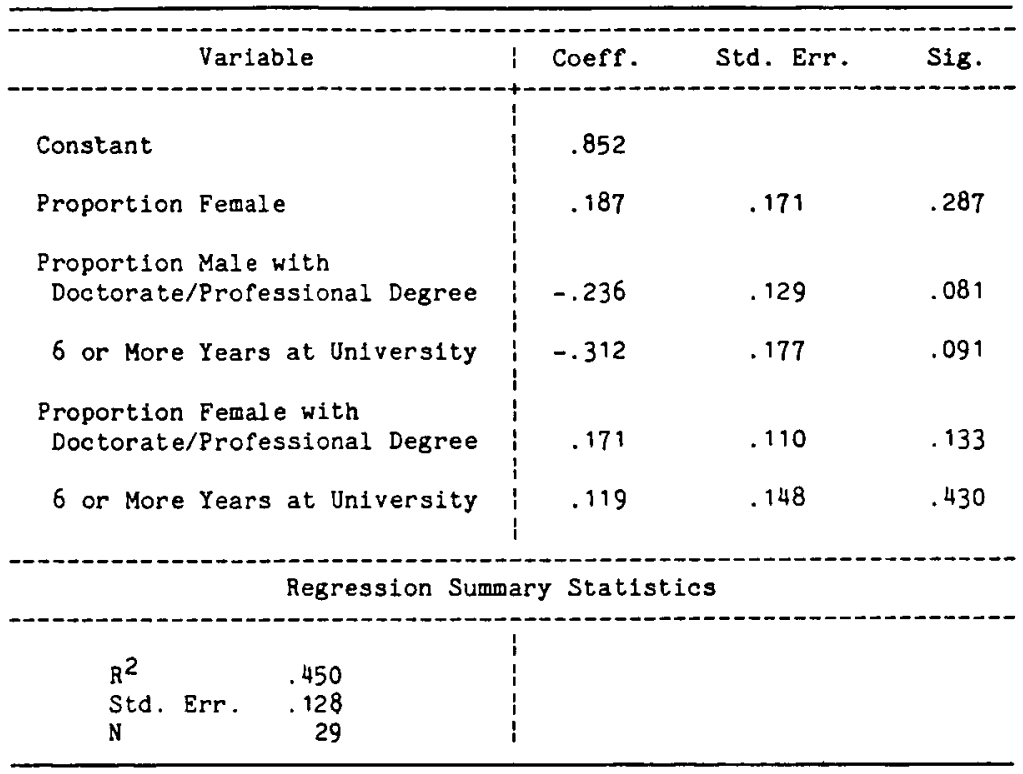

\section{SUMMARY}

Our findings do not support the competition, concentration, nor compensation hypotheses suggested by the literature on salary and sex composition levels. Rather, we find that the key to the sex-salary relationship lies in the connection between composition of the sexes and the context of achievement. Aggregate achievement levels and sex-related attainments, more particularly, are the clue to the determination of aggregate salary levels (male, female, and the female : male ratio):

(1) Sex composition is consequential for male salary levels, because male attainments vary with sex composition. Hence, if higher concentrations of women have a "contaminating" effect upon male salary, it is because of the low attainments of men in units with higher proportions of women.

(2) Sex composition is not critical in determining female salary levels. Female attainments, by themselves, are the important 
determinants; male attainments, on the other hand, are inconsequential. Same-sex attainments are the important salary determinants for females, as for males; but the variables are not so decisive, or strong, for women.

(3) Men are not salary-compensated for working with women. Units with higher proportions of women have more, not less, sexequivalent salaries. Moreover, a particular structure of sex related attainment, rahter than sex composition, is the more significant determinant of salary equivalence. These sex-separate achievement levels, rather than sex composition, determine salary equivalence.

Correspondingly, these cross-sectional data prompt us to consider that, for professionals, aggregate achievement levels may be a "mediator" of the longitudinal relationship between occupational sex composition and salary. As the occupational proportion of women increases, the male achievement levels may wane. And men's salary levels may, accordingly, dwindle. The changes in sex, achievement, and salary may follow one of two sequences:

(1) An increasing supply, and consequent concentration, of females may depreciate occupational status, so that men with less-distinguished credentials are then recruited.

(2) Or a declining occupation, suffering demise in functional importance, technical requirements, responsibility, and hence status, may be accompanied by the retreat of high-achieving males, and their replacement by females.

This latter sequence would be analogous to the proverbial retreat of white residents from, and entry of minority group residents into, a neighborhood already deteriorating in services, appearance, and amenity. The former sequence would be analogous to changes in group composition as a stage preceding neighborhood decline.

The data do not, on the other hand, indicate that male sex composition is an economic benefit shared by academic women and men alike. The presence and concomitant achievements of men are not advantageous for women's unit salary level. Hence, 
though only cross-sectional, these data for academics caution that an increasing male composition alone may not upgrade female salary levels in social work, nursing, library science, and other feminine professional sectors.

Rather, the data suggest that female salaries in feminine sectors may be raised by their own (female) attainment levels. This does not, however, indicate sex-equivalent salary for, or access to, those attainments. Achievement levels are not equally or equitably profitable for women and men alike; our educational and seniority attainments both raise male salary levels at a higherthan-female rate.

Furthermore, in academic, as in other institutions (Kanter, 1977), the opportunities to accrue credentials and demonstrate competence are not equally available to men and women. Sexrestricted sponsorship, support, and awards limit women's educational attainments (Feldman, 1974; Holstrom and Holstrom, 1974; Kjerluff and Blood, 1973). And the low ceiling appointments (i.e., temporal, visiting, and adjunct academic statuses) disproportionately held by women (Patterson, 1973) limit the accumulation of experience and the accrual of grants, offices, and other professional credentials. Hence, our sexspecific educational and experience levels reflects the organization's structure of opportunity, as well as the abilities and motivation of its members.

Thus, while our data indicate same-sex achievements as the dominant salary determinants for both sexes, the attainment measures and concomitant salary levels themselves reflect the sex-biased structure and organization of university work - as well as the academic aptitudes of its men and women. In this way, the data relationship between sex composition and salary structure is not only mediated by sex-attainment levels, but also modified by sex-attainment access.

\section{NOTES}

1. Unit refers to the university location classification: departments, colleges and schools, and other academic divisions. This classification is further specified in the method section. 
2. Our 1971 show that, among academics, the ratio of female: male salary ranges between a high of .89 for associate professors to a low of .78 for instructors, with lecturers $(.88)$, assistant professors (.83), and full professors (.82) falling between that range. Calculations from the university's gross salary statistics for 1978 show the same pattern and level of sex-wage disparity, with female : male salary ratios ranging from a high of .87 for associates to a low of .71 for instructors, with lecturers $(.82)$, assistant professors $(.80)$, and full professors $(.83)$ between.

3. The departments of the literary college are aggregated into arts and humanities; natural, physical, and biological sciences, including mathematics; social sciences; cultural area centers (East European, West European, Japanese, and so forth); museums, botanical gardens, and other departments, including the residential college. The other colleges and schools of the university are: (1) engineering: (2) medicine; (3) graduate studies administrative unit; (4) architecture and design; (5) business administration; (6) dentistry; (7) education; (8) law; (9) music; (10) natural resources; (11) nursing; (12) pharmacy; (13) public health; (14) social work; (15) secondary campus $A$ of the university; (16) secondary campus B of the university; (17) library science. The remaining noncollege units are: (1) general administration; (2) organzed research; (3) student services (including counseling, housing, job placement, and student organizations); (4) other instructional activity (including the extension service, center for continuing education for women, and continuing legal education); (5) hospital; (6) libraries; (7) state and public relations (including the alumni office, and publishing).

4. The data set does not include a tenure variable, nor does it contain a research productivity measure. A productivity measure would certainly strengthen our test, but its absence is not as restrictive in the single, as in a multiple, institution analysis of sex-related income levels. As we said earlier, institutional affiliation is a major factor differentiating the research productivity levels of academics generally, and of male and female academics more particularly. Consequently, the single-institution data hold constant at some threshold unit levels of male versus female productivity. We do not argue that interunit productivity is homogeneous. Obviously, it is not. Rather, we say that male versus female productivity is much less variable within, compared to between, institutions. However, male and female educational attainment, which is in our model, is no less disparate within this university than between academic institutions at large.

5. The size of the units varies from 2 academic employees (hospital) to 1371 employees (medical school). Observations were weighted by size so that the effect of each unit was proportional to the number of employees in the unit. In general, these coefficients were not significantly different from those of the unweighted regressions. The unweighted regressions are then the bases of the salary analyses.

6. The coefficient levels of the independent variables may be regarded as the income value placed upon a unit's ascriptive (sex) composition and/or a unit's achievement (education or seniority) level. These values of the independent variables are proportions (i.e., values between 0 and 1). Thus, a coefficient of 300 for doctoral/professional degree represents a $\$ 300$ income value for a $100 \%$ unit doctoral attainment; a $\$ 150$ value for $50 \%$ unit doctoral attainment; and a $\$ 75$ value for $25 \%$ unit doctoral attainment.

\section{REFERENCES}

ACKER, J. (1973) "Women and social stratification: a case of intellectual sexism." Amer. J. of Sociology 78 (January): 936-945. 
ASTIN, H. S. (1969) The Woman Doctorate in America. New York: Russell Sage. and A. E. BAYER (1973) "Sex discrimination in academe," pp. 333-356 in A. Rossi and A. Calderwood (eds.) Academic Women on the Move. New York: Russell Sage.

BARBER, B. (1952) Science and Social Structure. New York: Free Press.

BECKER, G. S. (1971) Economics of Discrimination. Chicago: Univ. of Illinois Press. (Originally published in 1957)

BERNARD, J. (1964) Academic Women. New York: Meridian.

BLAU, F. D. (1978) "The data on women workers, past, present, and future," pp. 29-62 in A. Stromberg and S. Harkness (eds.) Women Working: Theories and Facts in Perspective. Palo Alto, CA: Mayfield.

CAPLOW, T. and R. J. McGEE (1958) The Academic Marketplace. New York: Basic Books.

COLE, J. R. and S. COLE (1973) Social Stratification in Science. Chicago: Univ. of Chicago Press.

COLLINS, R. (1971) "A conflict theory of sexual stratification." Social Problems 19 (Summer): 3-12.

COSER, R. L. and G. ROKOFF (1971) "Women in the occupational world: social disruption and conflict." Social Problems 4 (Spring): 535-559.

EDGEWORTH, F. Y.(1922) "Equal pay to men and women for equal work." Economic J. 32 (December): 431-457.

FAWCETT, M. (1918) "Equal pay for equal work." Economic J. 28: 1-6.

FELDMAN, S. D. (1974) Escape from the Doll's House: Women in Graduate and Professional School Education. New York: McGraw-Hill.

FERBER, M. E. and J. W. LOEB (1971) "Sex as predictive of status on a university faculty." J. of Educ. Measurement 8 (Winter): 235-244.

and H. M. LAWRY (1978) "The economic status of women faculty: a reappraisal." J. of Human Resources 13: 385-401.

FOX, M. F. (1978) "Achievement, ascription, and reward: an analysis of academic sexwage variation." Ph.D. dissertation, University of Michigan.

FRIEDL, E. (1975) Women and Men: An Anthropologist's View. New York: Holt, Reinhart \& Winston.

FUCHS, V. (1971) "Differences in hourly earning between men and women." Monthly Labor Rev. 94 (May): 9-15.

HODGE, R. W. and P. HODGE (1965) "Occupational assimilation as a competitive process." Amer. J. of Sociology 71 (Novermber): 249-264.

HOLSTROM, E. and R. W. HOLSTROM (1974) "The plight of the women doctoral student." Amer. Educ. Research J. 11 (Winter): 1-17.

KANTER, R. M. (1977) Men and Women of the Corporation. New York: Basic Books.

KOHEN, A. and R. D. RODERICK (1972) "Causes of differentials in early labor market success among young women." Presented at the American Statistical Association, Montreal, Canada.

KOHEN, A. I., with S. C. BREINICH and P. SHIELDS (1975) Women and the Economy. Columbus: Ohio State University Center for Human Resource Research.

Y JERLUFF, K. H. and M. R. BLOOD (1973) "A comparison of communication patterns in male and female graduate students." J. of Higher Education 44 (November): 623632.

LIPSET, S. M. (1963) The First New Nation. New York: Basic Books.

LONG, J. S. (1978) "Productivity and academic position in the scientific career." Amer. Soc. Rev. 41 (December): 889-908. 
MADDEN, J. F. (1973) The Economics of Sex Discrimination. Lexington, MA: D. C. Heath.

MERTON, R. (1949) "Science and democratic social structure," pp. 550-561 in Social Theory and Social Structure. New York: Free Press.

MURLOCK, L. (1973) "Discipline variation in the status of academic women," pp. 255312 in A. Rossi and A. Calderwood (eds.) Academic Women on the Move. New York: Russell Sage.

PARSONS, T. and W. WHITE (1961) "The link between character and society," pp. 89135 in S. M. Lipset and L. Lowenthal (eds.) Culture and Social Structure. New York: Free Press.

PATTERSON, M. (1973) "Sex specialization in academe and the professions," pp. 313331 in A. Rossi and A. Calderwood (eds.) Academic Women on the Move. New York: Russell Sage.

REAGAN, B. and S. J. MAYNARD (1974) "Sex discrimination in universities: an approach through internal labor market analysis." AAUP Bull. 60 (Spring): 13-21.

ROSALDO, M. Z. (1974) "Woman, culture, and society: a theoretical overview," pp. 1742 in M. Rosaldo and L. Lamphere (eds.) Woman, Culture, and Society. Stanford, CA: Stanford Univ. Press.

RYTINA, J. H., W. FORM, and J. PEASE (1970) "Income and stratification ideology: beliefs about the American opportunity structure." Amer. J. of Sociology 75 (January): 703-716.

SNYDER, D. and P. M. HUDIS (1976) "Occupational income and the effects of minority competition and segregation: a reanalysis and some new evidence." Amer. Soc. Rev. 4 (April): 209-234.

STEVENSON, M. H. (1978) "Wage differences between men and women: economic theories," pp. 89-107 in A Stromberg and S. Harkness (eds.) Women Working: Theories and Facts in Perspective. Palo Alto, CA: Mayfield.

TAEUBER, A. F., K. E. TAEUBER, and G. G. CAIN (1966) "Occupational assimilation and the competitive process: a reanalysis." Amer. J. of Sociology 72 (November): 273285.

TAVRIS, C. and C. OFFIR (1977) The Longest War: Sex Differences in Persepective. New York: Harcourt Brace Jovanovich.

TSUCHIGANE, R, and N. DODGE (1974) Economic Discrimination Against Women in the United States: Measures and Changes. Lexington, MA: D. C. Heath.

WEISKOFF, F. B. (1972) "Women's place in the labor market." Amer. Econ. Rev. 62 (May): 161-165.

WILliAMS, R. M., Jr. (1960) American Society: A Sociological Interpretation. New York: Knopf.

ZELLNER, H. (1972) "Discrimination against women, occupational segregation, and the relative wage." Amer. Econ. Rev. 62 (May): 157-160.

ZUCKERMAN, H. and J. COLE (1975) "Women in American science." Minerva 13 (Spring): 82-102.

MARY FRANK FOX is Lecturer in Sociology at the University of Michigan. Her research interests-occupations, organizations, and stratification-are reflected in this article and other recent work on patterns of sex-rank and reward in organizations and society. Her book American Women at Work (coauthored with Sharlene Hesse) is forthcoming. 